\title{
Cloud of Things (CoT) based Parking Prediction
}

\author{
Nazish Razzaq ${ }^{1}$, Muhammad Asaad Subih², Madiha Khatoon ${ }^{3}$, Dr. Amir Razi ${ }^{4}$, Dr. Babur Hayat Malik ${ }^{5}$ \\ Nimra Ashraf ${ }^{6}$, Tehseen Kausar ${ }^{7}$, Rashida Tarrar $^{8}$, Muhammad Usman Sabir ${ }^{9}$, Syed Izaz ul Hassan Bukhari ${ }^{10}$ \\ CS and IT Department \\ University of Lahore, Gujrat Campus
}

\begin{abstract}
Cloud computing with an amalgamation of the internet of things (IoT) typically gave birth to an ideal field called Cloud of things (CoT). CoT maintains revolutionary services in every domain, but it has instantly become a rising star in smart transportation because a well-organized facility might present a challenge for dealing with the exponentially expanding people living in smart cities. Lack of management in transport can cause distress among people and nowadays parking has come to be one of the critical issues faced by the public daily. In this paper, we present a parking availability prediction model implemented within a geo-fence ranging from 100-150 meters based on cloud, IoT, and GIS. In contrast to present models, instead of offering no space or parking is full; our model accurately determines the ETA of a vehicle and checks the potential/chance of parking availability. It also calculates the time for the next parking space if the existing parking space accessibility is zero. Moreover, our model includes all the exogenous factors like weather, time zone conditions to gain prediction accuracy.
\end{abstract}

Keywords-Cloud computing; internet of things (IoT); parking; prediction; availability; Estimated Time of Arrival (ETA); Geofence; Geographic Information System (GIS)

\section{INTRODUCTION}

Transportation establishes an essential foundation for our present society. The transportation system performs a vital role in personal mobility and for the financial development of all countries. Modern society has been confronting more environmental problems today, i.e. traffic congestions, higher fuel costs, pollution, and parking [2]. Rapid growth of traffic and limited transport resources has caused urban traffic pressure on society [16]. Modern vehicles nowadays are prepared with innovative implanted technologies like sensors, GPS, and communication capabilities [18]. Cloud computing and the internet of things (IoT) has provided various services to minimize traffic congestion as well as management problems [19]. The progress in cloud computing and the internet of things (IoT) have given a chance to a new field called Cloud of Things (CoT) which adopts both technologies to improve the expanding transportation issues, like significant traffic, blockage, and vehicle security [16] [17]. CoT further uses Geographic Information System (GIS) for managing transportation. The GIS helps to manage and monitor the land information [3].

In the transportation field, parking is considered a key segment [3]. Due to the immense growth in the world's population, there has been a massive increase in the usage of public and private vehicles [1]. Parking has remained a standard problem due to the constant increase in the use of vehicles everywhere like airports, malls, offices, hospitals, etc.
[8]. Traffic congestion due to widespread conveyances on the road is a distressing hassle at an international level and it has been developing exponentially. The primary cause of congestion is automobile parking [3].

When drivers are unable to find parking spots, they get frustrated and leave their cars in the middle of roads leading to problems such as "traffic congestion or Illegal parking" [2]. The Global Parking Survey, carried out by International Business Machines back in 2011, showed that on an international scale 20 drivers struggle while finding parking spaces daily, where 6 out of 10 give up immediately, and they are looking for parking make up about $30 \%$ of the city traffic [1] [6]. With the evolution of technology in the past few years, many means of transports and parking industries have made use of these technological advancements to create parking systems. With the use of cloud computing, IoT, sensors, GIS, and simultaneous data gathering, modernized parking systems allow drivers to get information about available parking space anytime anywhere [7]. These smart parking structures further assisted with RFID, WSN, and NFC makes it easier for a driver to find an available spot [3].

In this article, we propose a model for parking space occupation prediction in a particular fenced area using the Cloud of Things (CoT) which represents the combination of various advanced technologies. We also present a simulating evaluation of the subsequent model with a proper view.

The remainder of this paper is organized as follows. The next section discusses technological background automobile services. Section III presenys the past work done on parking prediction. Section IV describes our evaluation methodology. Section $\mathrm{V}$ demonstrates the simulative view of our model. The results are displayed in Section VI. Finally, Section VII concludes this paper.

\section{TECHNOLOGY BACKGROUND}

\section{A. Cloud Computing}

It represents an innovative on-demand model that delivers hundreds of services over the web with a pay-as-you-go scheme [17]. Cloud computing has guaranteed the accessibility of information to everybody through the ondemand model. It enables the end-users to store, access, and process information over the web. It provides all the facilities without demanding intense investments [18]. Gartner Group and International Data Corporation (IDC) consider cloud computing a peak IT trends with high business potential ranging from $\$ 40-100$ billion yearly [20]. Cloud computing could be a bundle of three distinct services named as 
Infrastructure as a Service, Platform as a Service and Software as a service [18]. It is exemplary a benefit in various areas but it has helped a lot to revolutionize the shape of transport services within the automobile industry [19]. Cloud-based urban control systems help in traffic administration and control, road routing, vehicle safety, and parking [20].

\section{B. Internet of Things}

It is a promising technology to revolutionized human life with remote monitoring by connecting everything to the internet [16]. IoT helps in tracking, controlling, and monitoring remote gadgets associated with the internet. Things in IoT refer to any object which needs to be tracked i.e. lights at home, cars on the road, products in stock [17]. IoT practices three emerging technologies to track things i.e. Identification which uses RFID bar code to recognize the items and their status. Sensing and Communication use WSN to track the varying category of the things and then transfer this information [16] [18]. IoT resolved traffic congestion, accident detection, road safety, and parking problems with wireless remote sensing [19].

\section{Geoinformation System}

It is a geographical structure used to capture, store, control, and observe a broad range of spacial land information [5]. The geographical material of a particular area can be accessed with the help of GPS, WSN to organize, analyze, and interpret according to the specific choice of the problem. GIS helps in getting parking area information via sensors and makes it easier for drivers to find parking space [3].

\section{Technology Innovation in Automobile Services}

Cloud computing emerged with IoT has caused the transformation into the automobile field. In many scenarios, cloud computing and IoT work together for better business processes and operations to achieve customer satisfaction [17]. This innovative and versatile field is better identified as the Cloud of Things (CoT). Cloud computing with an accomplice of the IoT gathers data from remote areas with wireless sensors. At that time information can be utilized by the providers to assist drivers to discover the unoccupied spot remotely [19]. The mixture of technologies is the middleware pattern of advanced parking systems in the present era [20].

Table I shows how parking traditions changed over time. In traditional models finding parking space was a manual process and now due to advanced models of automobile, it has become easier to find the parking space ahead of time.

Fig. 1 and Fig. 2 show the mixture of two latest technologies cloud computing and the internet of things anonymously known as the cloud of things (CoT). CoT works as middleware that operates some or all features of both technologies. Cloud provides database services while IoT helps in a better interactive interface. Collectively they perform a better job than individually.
TABLE I. TRANSFORMATION OF AUTOMOBILE MODEL

\begin{tabular}{|l|l|l|}
\hline Service & Traditional Model & Advance Model \\
\hline Parking & $\begin{array}{l}\text { Driver roams around the } \\
\text { parking lot to find the } \\
\text { unoccupied spot. }\end{array}$ & $\begin{array}{l}\text { Track vehicle } \\
\text { movement and road } \\
\text { conditions. }\end{array}$ \\
$\begin{array}{l}\text { Manual receipt of the } \\
\text { parking. }\end{array}$ & $\begin{array}{l}\text { Assist driver with real } \\
\text { time parking lot } \\
\text { If parking is full, no } \\
\text { chance of advance } \\
\text { parking. armation. } \\
\text { Driver can not get } \\
\text { information about } \\
\text { parking occupancy until } \\
\text { s/he reaches into lot. }\end{array}$ & $\begin{array}{l}\text { If the parking is full, } \\
\text { driver gets alert ahead } \\
\text { of time. } \\
\text { Assist driver to find the } \\
\text { parking spot based on } \\
\text { preference. }\end{array}$ \\
&
\end{tabular}

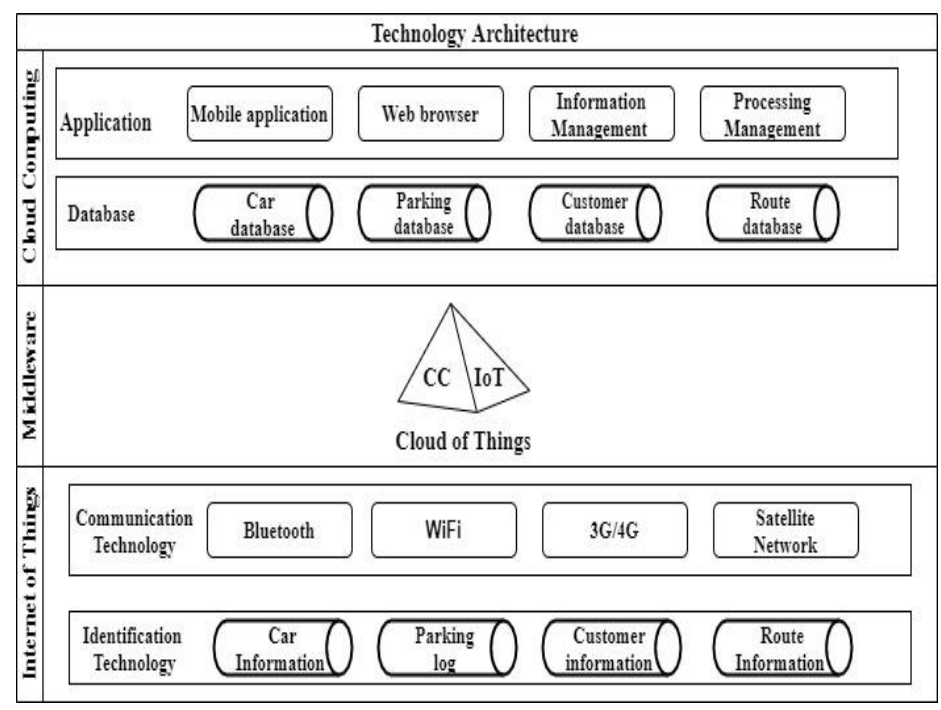

Fig. 1. Innovative Technology Architecture.

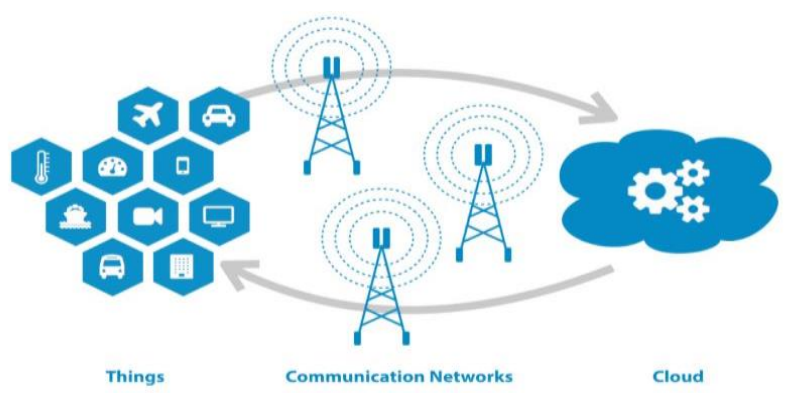

Fig. 2. Cloud of Things (CoT) Mechanism. 


\section{RELATED WORK}

Parking is the key feature of transportation, if the parking lot lacks anything; it can shake up everyday life [4]. Many techniques are invented to overwhelm this critical issue. But all these systems are not real-time which means parking can only be available if the driver has a reserve spot in advance [5] [9] [10]. The problem was first highlighted in 2007. The authors addressed, "Automation and Modernization of Car Parking Management" and proposed a framework based on the queuing model. Markov Chain approach operating the two merges technologies WSN and RFID. This approach contains information such as occupied parking spots, parking, and the arrival rate of the vehicle. The parking rate reflects the lot's current state and the arrival rate; ETA calculation is needed for prediction. Since it operates a similar queue-based structure so the stream of inward vehicles is a counting procedure. Due to the finite capability of the lot and predictability is calculated through information exchanges among vehicles in a row. Markov Chain senses and tracks the vehicle whenever it enters a detecting field and transmits the signals of availability to the driver. This represents the individual number of vehicles parked in the lot simultaneously. When the lot is full but the line maintains some vehicles, it rejects the parking request and informs parking is unavailable. Markov Chain additionally includes guidance about parking availability, automatic payment, security and vandalism detection, etc. [10].

The Global Positioning System (GPS) technology is identified as the rising star for predicting parking availability; not only it provides navigation but also helps in discovering the closet lots, the existing position of the vehicle, and instruct towards the desired stop. The availability via GPS navigation system asks the driver his current location and destination. For computing the provisional distance of the vehicle by using the shortest path on which the vehicle will reach the target. Based on past occupation, information of the car parks, and estimated arrival time the probability of zones is predicted. These prediction approaches use the finest granularity of data and consider every bit of data in prediction at the given instant of time [11].To improve urban infrastructure and locationbased services observation, and modeling human movement in an urban environment remains a crucial factor. Analyzing and uncovering human behavior patterns results in better predictive models. In Spain: Barcelona, a bicycling system based on spatiotemporal data of the bicycle stations and their parking patterns for 13 weeks were implemented. To gather the social and geographic viewpoints of the city and predict future bicycling station usage behavior, which compares to human movement in the city. This system used Bayesian Networks to gather the spatiotemporal data of human behavioral patterns Barcelona's public into three clusters i.e. outgoing, incoming, and flat. The outgoing cluster contains the order of people leaving for work from seven to eight AM and lunch breaks from two to three PM. The incoming group supports the data in operating time from seven to eight AM and early leaving time from one to two PM. The flat cluster station periodically is $66 \%$ full but mostly $15 \%$ available due to Barcelona's incline topography because people avoid parking at higher altitudes above on sea levels. This system predicts short and medium-term parking availability with $80 \%$ accuracy. Where the short-term forecast is up to 5 minutes and the long-term forecast is up to 2 hours or 120 minutes utilizing 10-12 weeks of historic information. Shared bicycling usage is considered as a source of movement, and the flow of the city [12]. Exogenous factors like (weather, daytime) affect the mobility and use of resources [12] [13].

Barcelona shared bicycling model, further expanded in the city of Ireland: Dublin named the Dublin bike system but used General Additive Model (GAM) a class of the algorithms incorporating exogenous variables as well. Dublin bike system targeted 550 bikes and 44 stations which typically work from 05:00 AM till 00:30 AM every day. GAM is a two-stage prediction model that discovers the accessibility demands on various time stamps and calculates the allocation of remaining time for another possible parking space if current accessibility is zero. It hits the highest point on weekdays through morning and evening rush hours from 08:00 AM to 05:00 PM as well as during lunch hours 12:30 PM. On the ends of the week, the request lies from 07:00 AM till lunchtime and diminishes a short time later. The climate data is collected half-hourly and categorized into (rainy, foggy, normal) temperature ranges 1$21^{\circ} \mathrm{C}$ for bike riders. This system calculates the prediction for three-time scales: 1) short term: prediction up to 5 minutes, 2) medium-term: up to 1 hour, 3) long-term: up to 24-hours. This system also provides the journey planner to the driver and helps him chooses the desired route from multiple routes according to his time constraints [13].

Intelligent Parking Assist (IPA) works on a similar Poisson process and communicates through the vehicle to infrastructure (V2I) and infrastructure to vehicle (I2V) for receiving information from the environment. It finds a reasonable spot based on all individual's preference and determine that behavior. The most suitable spot is determined using the chi-square goodness best fit method. The optimization prediction algorithm of IPA is probabilistic and works in real-time and on historical data. This framework maintains an advantage over all past models that; it operates on-street, off-street garages, also free spaces to estimate parking accessibility on the base of drivers expected arrival time to his/her target [14].

The cloud-based intelligent system is a three-tier architecture which dominates on all systems because it not only encourages the driver to discover, pick, and prevent the 'most suitable' accessible parking lot that is driving a car in a specific region, but also provide the driver with navigation directions for reaching this zone too. At the first tier, a user interface provides information about cloud-based services. The second tier is the communication layer; which possesses various wireless technologies and acts as a link between the user interface and the cloud layer for the trade of the data. Cloud Tier contains information storage space and computing resources for the parking service. It collects the 'big data' of possible lots, parking region, car area, user area, and profiles, etc. Each parking lot contains sensors whenever a car enters its proximity, sensors communicate with the cloud layer to check the lot occupation level then transmit the available spots (if any) direction to the driver [15]. 
Table II represents the comparsion of all the previous parking models, how this problem was solved with the help of technologies and the limitations of previous models. Not only these models solved this problem but also had limitations in their working.

TABLE II. COMPARISON OF PREVIOUS PARKING METHOdOLOGIES

\begin{tabular}{|c|c|c|c|}
\hline Sr\# & Name of paper & Technique & Limitation \\
\hline 1 & $\begin{array}{l}\text { Predicting parking lot } \\
\text { occupancy [10]. }\end{array}$ & $\begin{array}{l}\text { Markov Chain } \\
\text { Approach }\end{array}$ & $\begin{array}{l}\text { 1. It is based on the } \\
\text { exchange of } \\
\text { information among } \\
\text { vehicles in a queue for } \\
\text { parking occupancy } \\
\text { which causes } \\
\text { connectivity and } \\
\text { storage issues. } \\
\text { 2. Vehicles in the } \\
\text { queue are not } \\
\text { guaranteed to get } \\
\text { parking every time. }\end{array}$ \\
\hline 2 & $\begin{array}{l}\text { Intelligent GPS-based } \\
\text { navigation system [11]. }\end{array}$ & $\begin{array}{l}\text { GPS based } \\
\text { system }\end{array}$ & $\begin{array}{l}\text { 1. Parking availability } \\
\text { is dynamic and can't be } \\
\text { deterministic which } \\
\text { means accessible spots } \\
\text { at the period of } \\
\text { decision-making cannot } \\
\text { be guaranteed to be } \\
\text { available at the arrival } \\
\text { time. } \\
\text { 2. This model is } \\
\text { unanalyzed in the } \\
\text { situation when several } \\
\text { vehicles search for the } \\
\text { lot in real-time. }\end{array}$ \\
\hline 3 & $\begin{array}{l}\text { Predicting the pulse of } \\
\text { the city through shared } \\
\text { bicycling [12]. }\end{array}$ & $\begin{array}{l}\text { Prediction via } \\
\text { sensing } \\
\text { methodology }\end{array}$ & $\begin{array}{l}\text { 1. This model doesn't } \\
\text { consider circumstantial } \\
\text { features like weather, } \\
\text { time-zone, season, } \\
\text { special events. } \\
\text { 2. It only works during } \\
\text { day hours. }\end{array}$ \\
\hline 4 & $\begin{array}{l}\text { Predicting waiting } \\
\text { times for shared } \\
\text { bicycles and parking } \\
\text { lots [13]. }\end{array}$ & $\begin{array}{l}\text { Generalized } \\
\text { Additive } \\
\text { method }\end{array}$ & $\begin{array}{l}\text { 1. There is no facility } \\
\text { of reserving space in } \\
\text { advance. } \\
\text { 2. This model does not } \\
\text { work for cars. }\end{array}$ \\
\hline 5 & $\begin{array}{l}\text { Intelligent parking } \\
\text { assists [14]. }\end{array}$ & $\begin{array}{l}\text { Prediction } \\
\text { Algorithm }\end{array}$ & $\begin{array}{l}\text { 1. Error ratio in } \\
\text { prediction on } \\
\text { average is } 2.8 \% \\
\text { calculated by the } \\
\text { Monte Carlo } \\
\text { algorithm. }\end{array}$ \\
\hline 6 & $\begin{array}{l}\text { Cloud-based parking } \\
\text { services for smart cities } \\
\text { [15]. }\end{array}$ & $\begin{array}{l}\text { Cloud-based } \\
\text { parking system }\end{array}$ & $\begin{array}{l}\text { 1. This model covers a } \\
\text { partial area for } \\
\text { prediction. }\end{array}$ \\
\hline
\end{tabular}

\section{Methodology}

This section contains an algorithm for the prediction of parking space occupation. Our model works on real-time parking availability data based on geofence. Geo-fencing allows the specification of geological areas and produce entry/exit events when a device spans the border [5]. This model uses the blend of multiple technologies like cloud computing, the internet of things, GPS, within a certain geofence. The minimum range of geo-fence is considered as 100-150 meters around a parking lot. The driver gets inform whenever his/her vehicle crosses the threshold of the geofence zone and can request parking. If the parking request is made then the system checks the current state of the parking lot occupancy from the CoT database, calculates the no of vehicles that are about to leave the lot is greater than 10 minutes, and lastly free parking spots available at that timestamp. Our model tells the driver whether there is potential for parking availability or not. The time customers park their vehicles, both driver and owner, are notified with information about that particular spot through push notifications. Additionally, when a driver leaves a parking spot and drives away, it indicates that free space should be available again, so there is no need for drivers to roam around again and again to find parking [9].

Fig. 3 shows the flow of proposed model. This model is a two way process, it either entertains the parking request or gives exit call if there is no potential of availability. This model takes the request and responds according to the ETA or given time parameters of the demand. This model has an innovative feature which is determination 10 minutes stamp of ETA, this features enhances the quality of finding parking availability as it makes possible that maximum vehicles get the chance of ocuupaying the parking space.

The proposed model also calculates the waiting time prediction if parking is not available instantly. This model includes all exogenous factors, i.e. weather and day-hours.

Fig. 4 shows how parking requests are made and how the data is stored. The data streams of parking requests are stored in the form of tuples. The necessary parameters which are needed to allocate space are also ingested in tuples. In data contextualization, assignment of the parking spot is done on the basis of traffic conditions and ETA of the vehicle.

\section{A. Dissemination of Parking IoT Information}

In our approach, four values for each parking lot are considered. These are timestamp, the capacity of the lot, the number of parking spots currently engaged, and the ETA of the vehicle.

\section{B. Prediction of Availability}

Our model predicts three kinds of availability predictions using signs given below:

- $P$ indicates that the parking spot is available in the lot.

- Phows that parking is unavailable at that time but calculates the ETA of the vehicle to check whether the 
parking can be provided or not. If the ETA is greater than 10 minutes and there is a vehicle that will empty its occupied spot within these minutes. There is a chance of availability.

\section{- $P$ notifies that parking is full.}

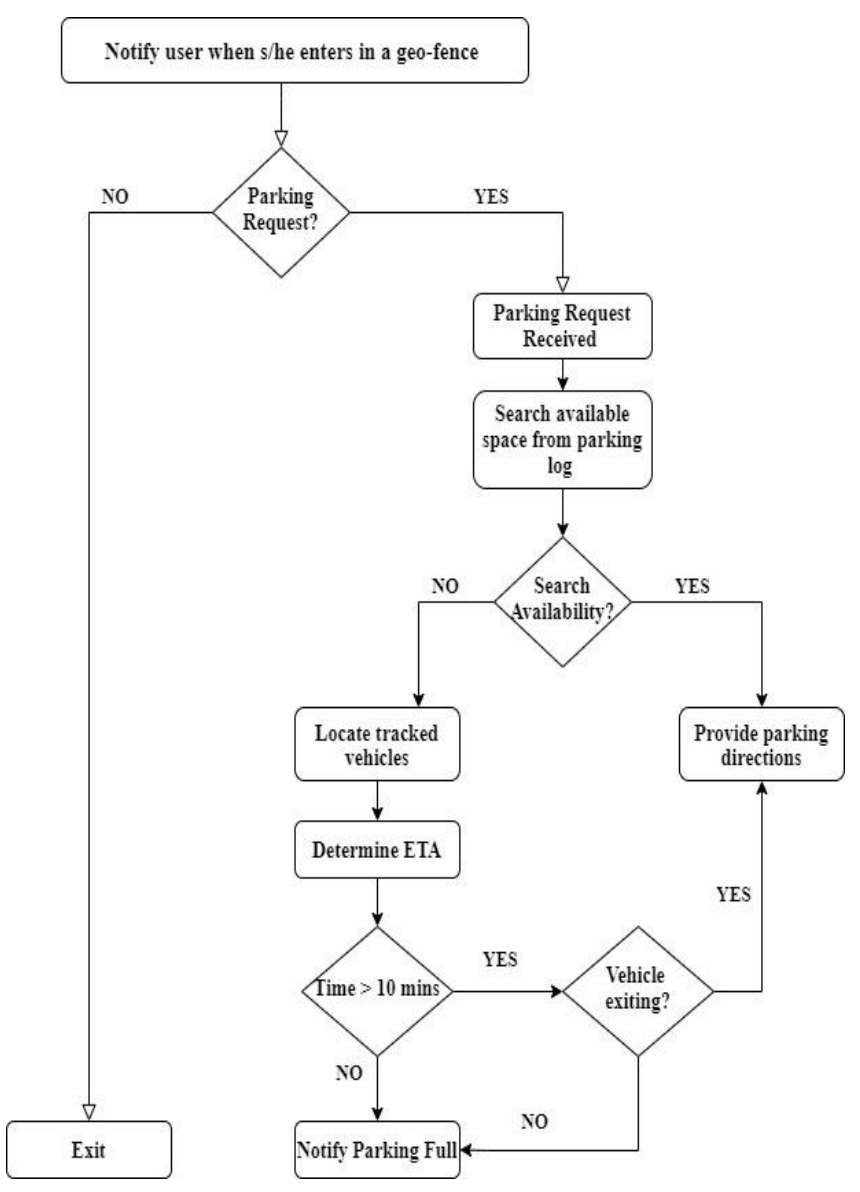

Fig. 3. A Proposed Methodology for Parking Prediction.

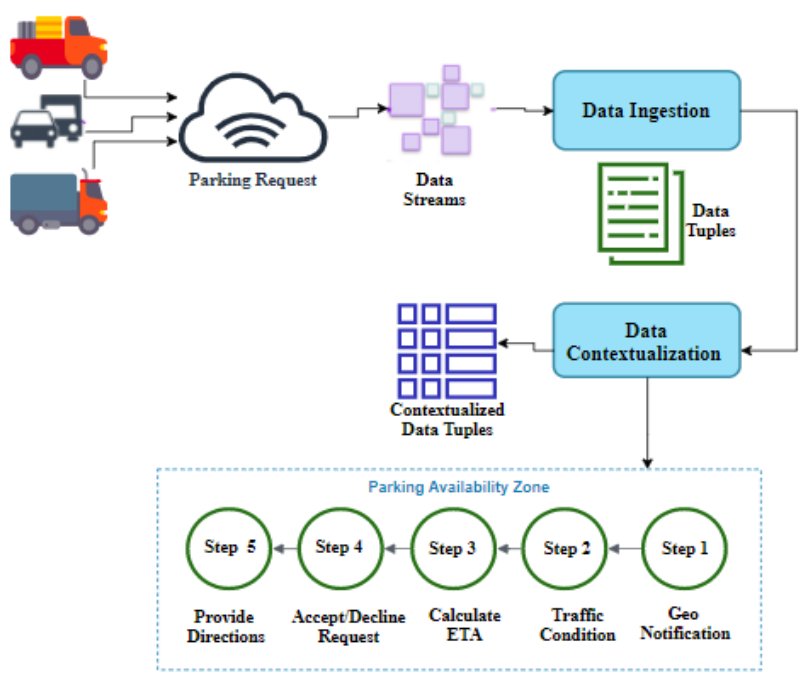

Fig. 4. Automated Parking Prediction on CoT-GIS Platform.

\section{Prediction of Waiting Time}

This model calculates the waiting time for the next convenient spot if the current predictions indicate no spot is vacant at the moment. We assume that the arrival time-varying intensity. The intensity is typically extraordinary during active times such as morning or evening rush hours so there is a tremendous fluctuation in parking requests. In contrast, it is low late at night or early morning at the end of the week [13].

\section{Weather Factors}

Since our model is implemented using a combination of technologies so the weather would not affect the predictability. In most scenarios weather, is considered as the constant.

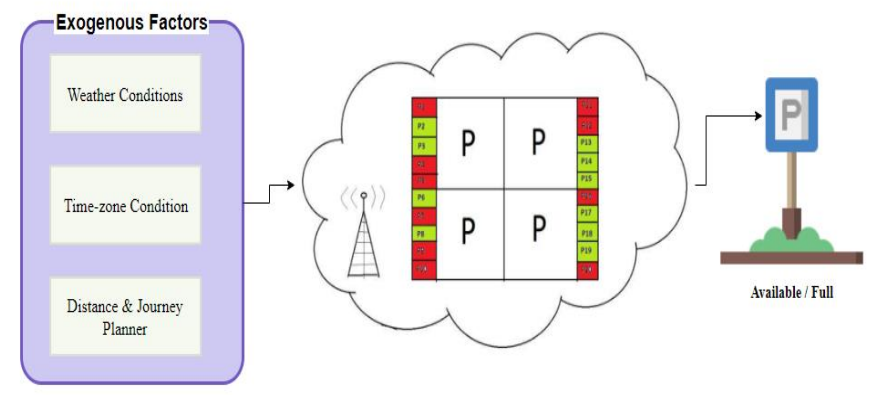

Fig. 5. Constant External Factors in Parking Prediction.

Fig. 5 shows that the projected model considers all external variables while predicting the parking availability. The CoT framework considers all the inputs from the user as well as external factors, i.e. weather, time-zone, distance calculation, and provide results with high accuracy.

\section{Simulation}

This section contains the stimulative view and evaluation of the proposed model. This model does not require any technology but makes better use of embedded technologies such as GPS and WSN for parking prediction. GPS and WSN also do not need high power or cost. Fig. 6 below shows the states of simulation for smart parking in the geo-fenced area whereas Fig. 7 shows the mechanism of simulative states. The detailed simulation represents states of the vehicle which are looking for parking within a smart city and geo-fence. State 1 indicates the detection of a vehicle in a particular area through wireless sensors. State 2 portrays the user request for parking. State 3 directs the parking directions to the driver if there is any unoccupied space. State 4 asks the driver for parking fees which is optional and depends on the parking lot administration. State 5 checks the identity of the driver via license for safety purposes. Finally, state 6 concludes the workflow and gives access to the driver towards the parking spot. In case, if the parking is not available, it enables users to book parking in advance within the next 24 hours. The new addition to the presented model is that with the help of CoT it provides potential parking which means if any vehicle from the parking lot is about to exit to less than 10 minutes, the requesting vehicle/driver can get that spot. This feature differentiates our model from all other classical models. 


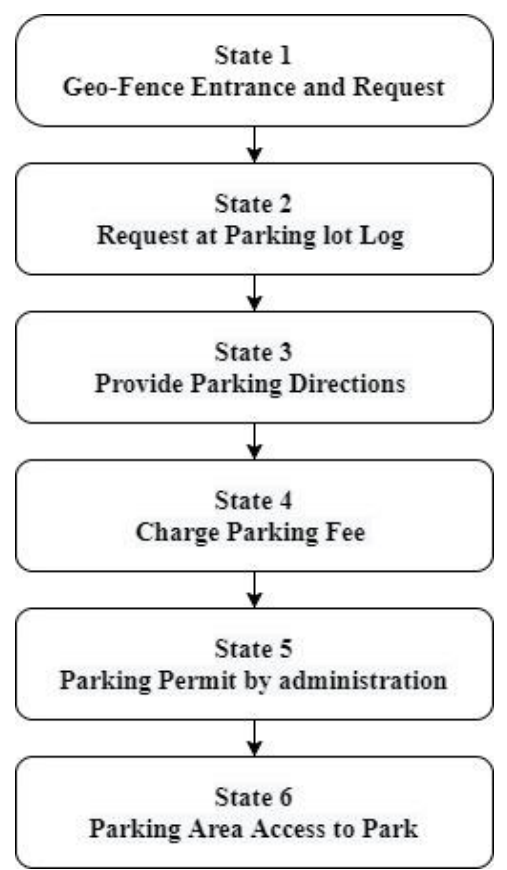

Fig. 6. Block Diagram of Simulative Parking States.

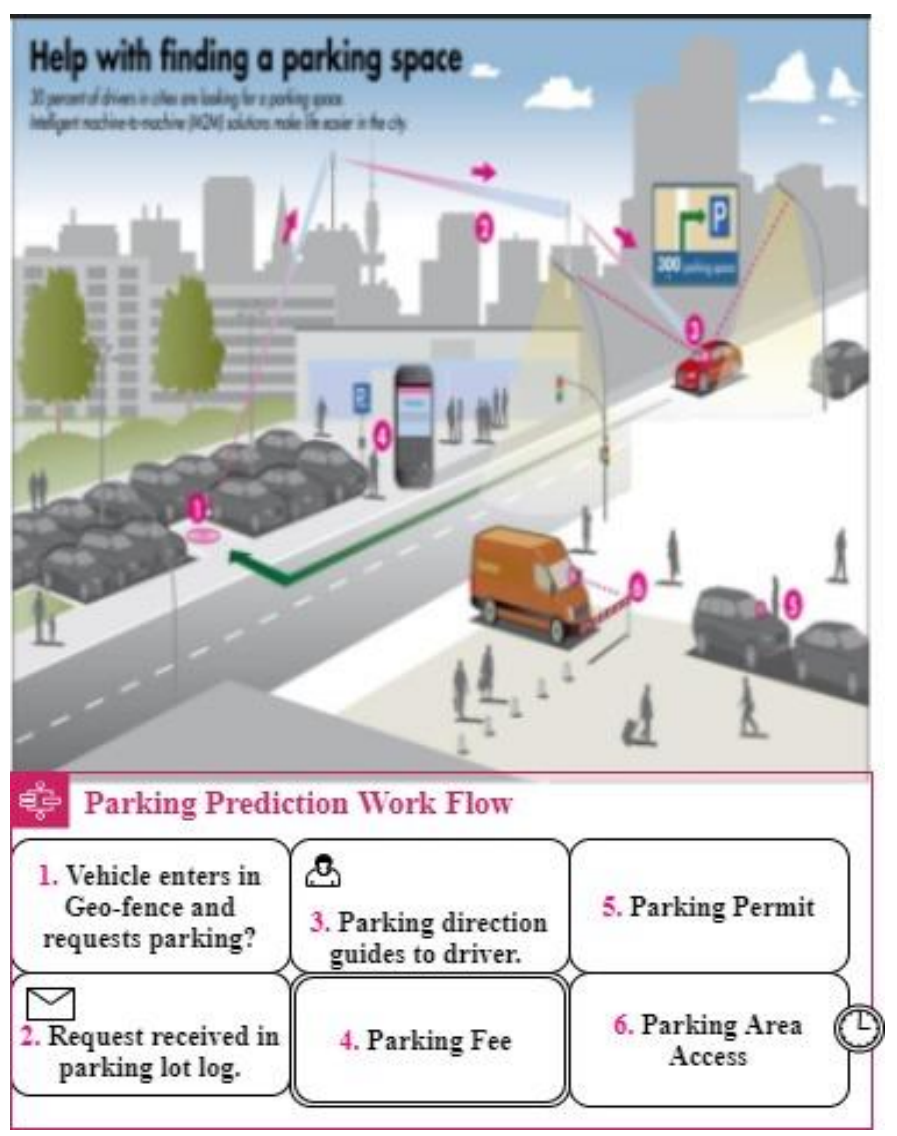

Fig. 7. Parking Availability Prediction Simulation.

A. State 1

This state shows how certain vehicle sinks in a particular geofenced area and its detection. Fig. 8 shows how the sunk vehicle can request a parking spot.

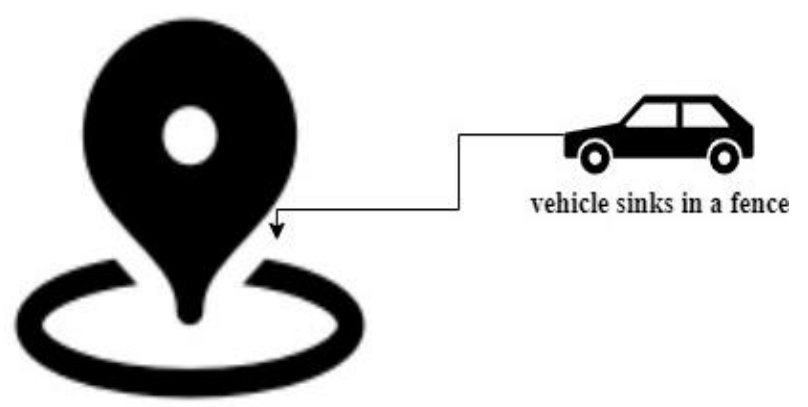

Geo-fence(100-150m)

Fig. 8. Vehicle Sinks in a Virtual Geofence.

\section{B. State 2}

The vehicle entered in a geo-fence can request parking in a near-by parking lot within a geo-fence area only. Fig. 9 shows the parking request made by the vehicle in a geo-fenced area.

\section{State 3}

If the user has requested parking and parking lot log has processed the request which results either in parking directions or parking is not available at the spot. Fig. 10 shows how the proposed model gives parking direction and its coordinates if parking is available.

\section{State 4}

This phase depends on parking lot administration if they charge fees the requester will pay the specific amount either to parking guard or via banking app based on driver's preference. Fig. 11 shows the payment methods for parking.

\section{E. State 5}

In this state, the parking guard will permit the driver by checking his/her driving license for safety purposes. Fig. 12 shows the basic inspection of vehicle entered in a parking lot which is done manually by guards as well as machines.

\section{F. State 6}

After the checking of the vehicle, the driver will get access to the parking spot along with parking coordinates. Fig. 13 concludes the whole procsess of parking by using coordinates to park in the allocated space.

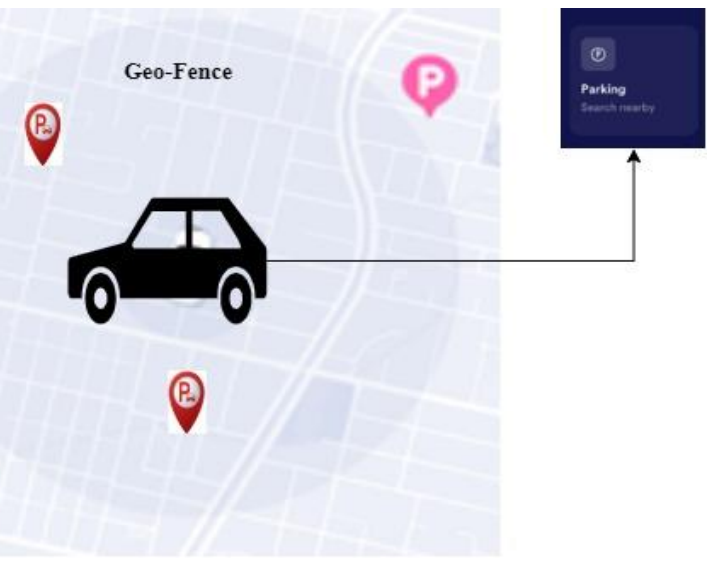

Fig. 9. Vehicle Requests Parking within Geofence. 


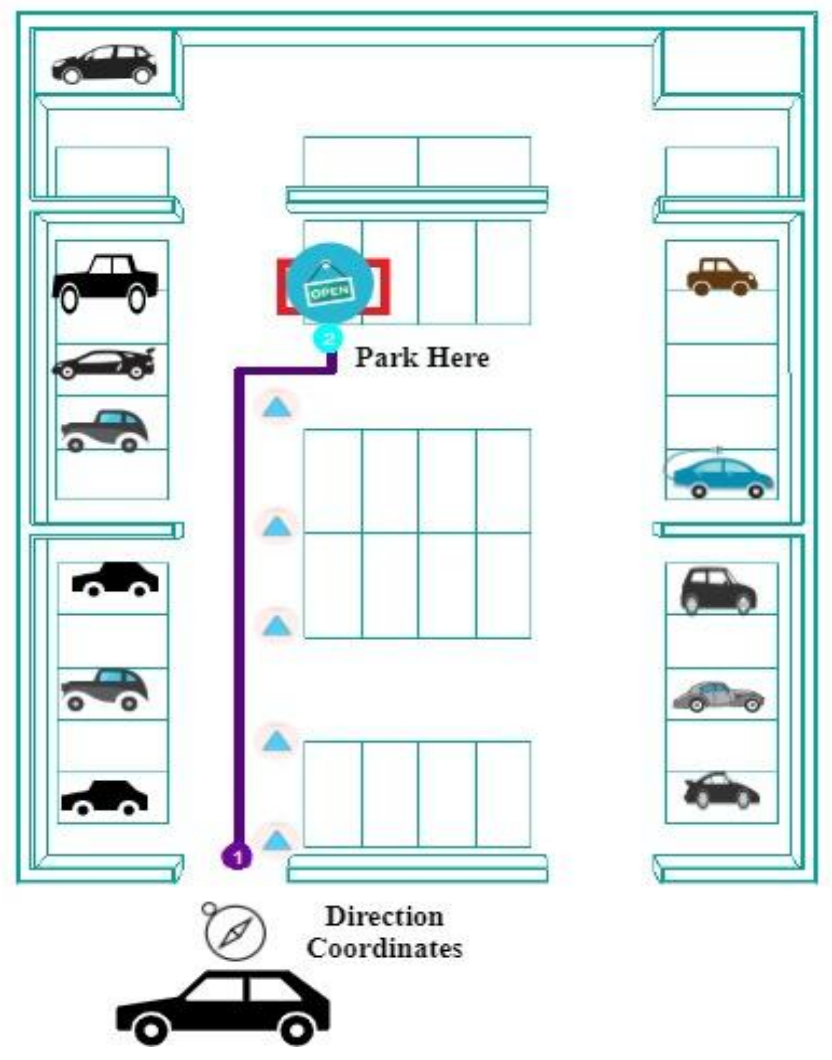

Fig. 10. Vehicle Directing Towards the Parking Spot.

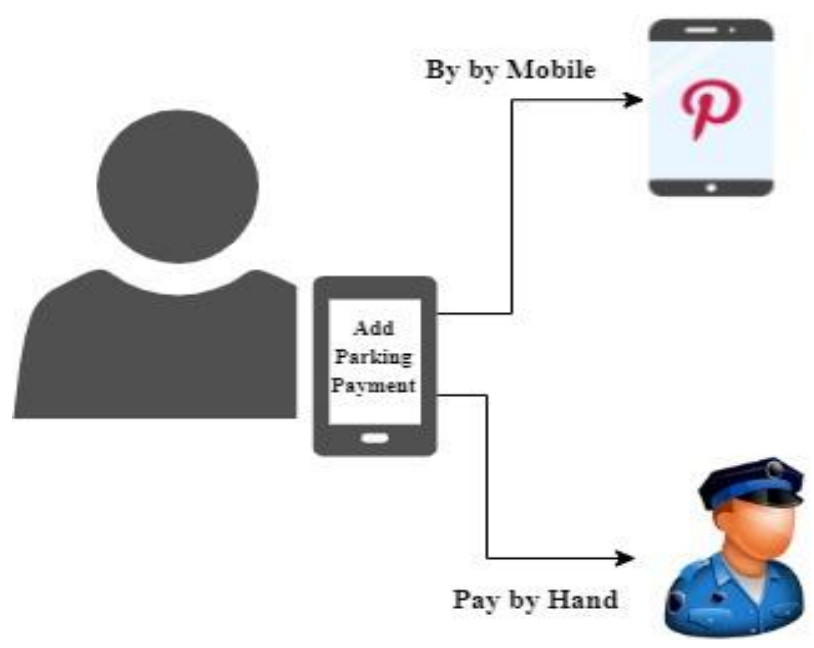

Fig. 11. Two Methods for Parking Payment.

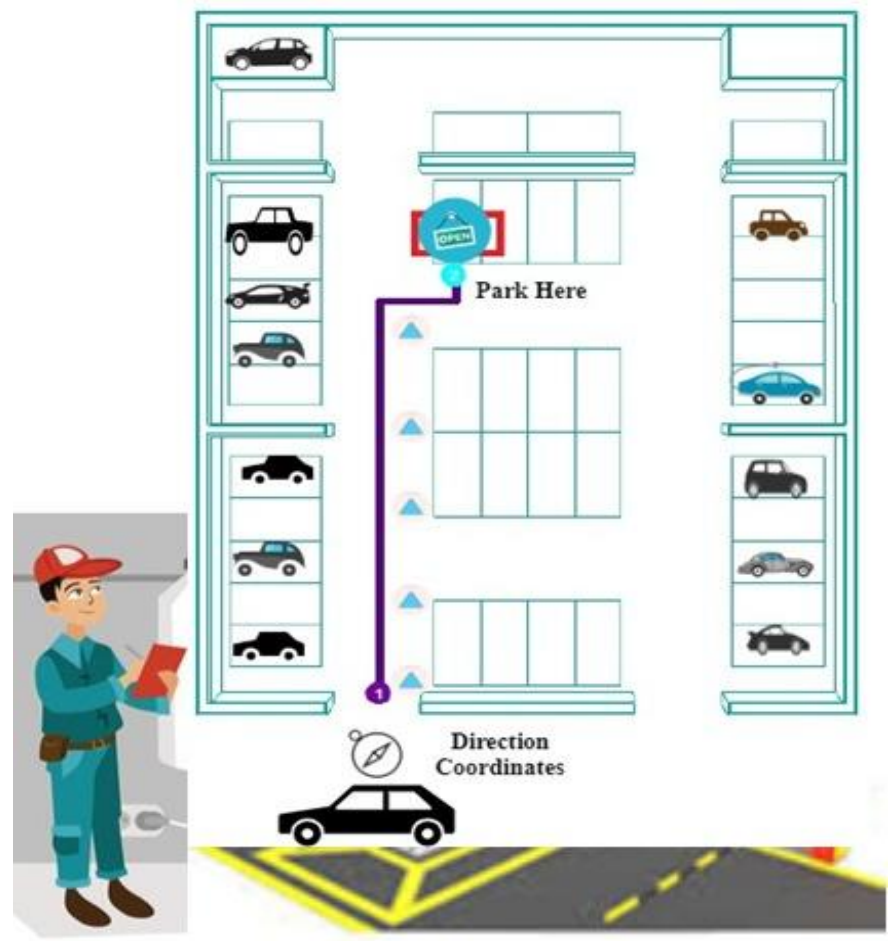

Fig. 12. Parking Permit by Parking Administration.

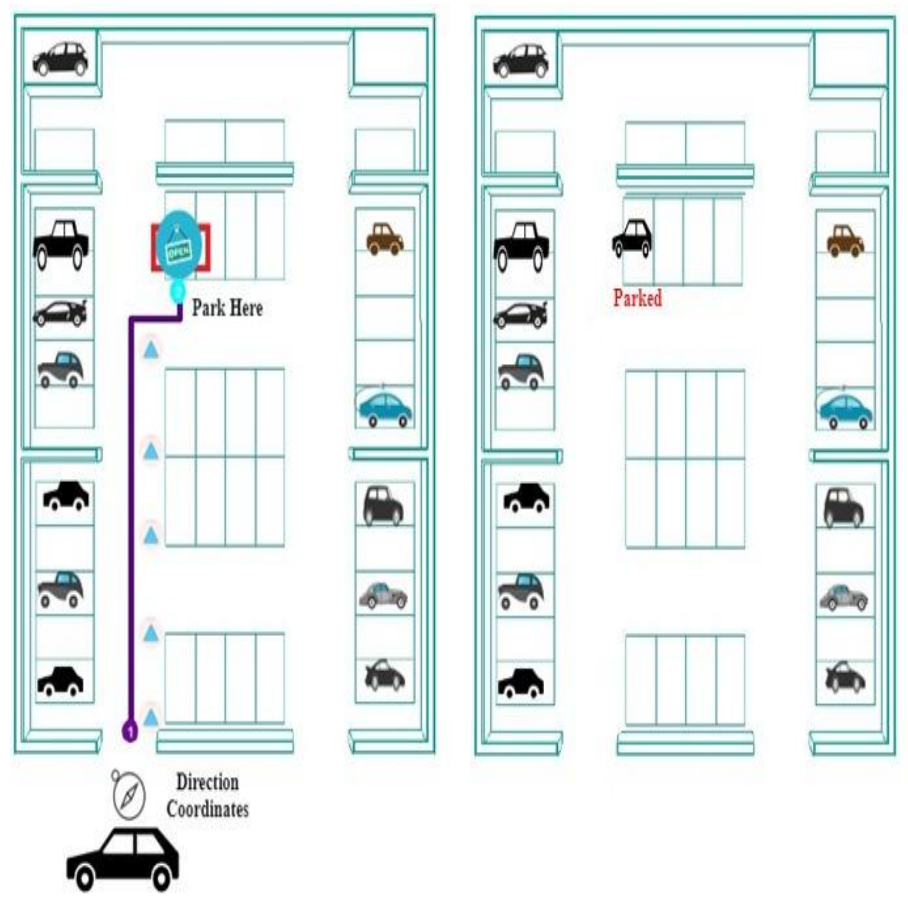

Fig. 13. Parking Area Access to a Vehicle Parked. 


\section{RESULTS}

The parking simulation is implemented on one of the parking lots of Pakistan named as Fatima Jinnah /Capital / F-9 Park situated in F-9, Islamabad, Islamabad Capital Territory, Pakistan coordinated as $33.7018^{\circ} \mathrm{N}, 73.0228^{\circ} \mathrm{E}$. This parking lot has a parking capacity of 440 vehicles at a time. The parking trends of this parking lot over 7 days of the week and 24 hours per a day: (1) During working days (Monday to Friday) the parking demands lie from $12 \mathrm{PM}$ to $6 \mathrm{PM}$ which is off timing from working areas i.e. office, universities, etc. (2) During weekends (Saturday and Sunday) parking demands rise from 3 PM to 6 PM with little decrease till 9 PM since it's a park so people on holidays come here to spend time with their families. In order to test our model we built simulation on the below mentioned scenario.

Result Dicussion of Demo: A car enter in a geofence area. A map view of the parking lot is show to the driver. The model shows all possibilities of parking shown in Fig. 17. If the driver wants to get a parking spot s/he can request and Fig. 18 will be the result of hisparking request. System will show free, occupied and potentially available spots along with parking block, time and charges. The driver will further be able to get the direction coordinates and parking track of his assigned parking spot to park the vehicle.

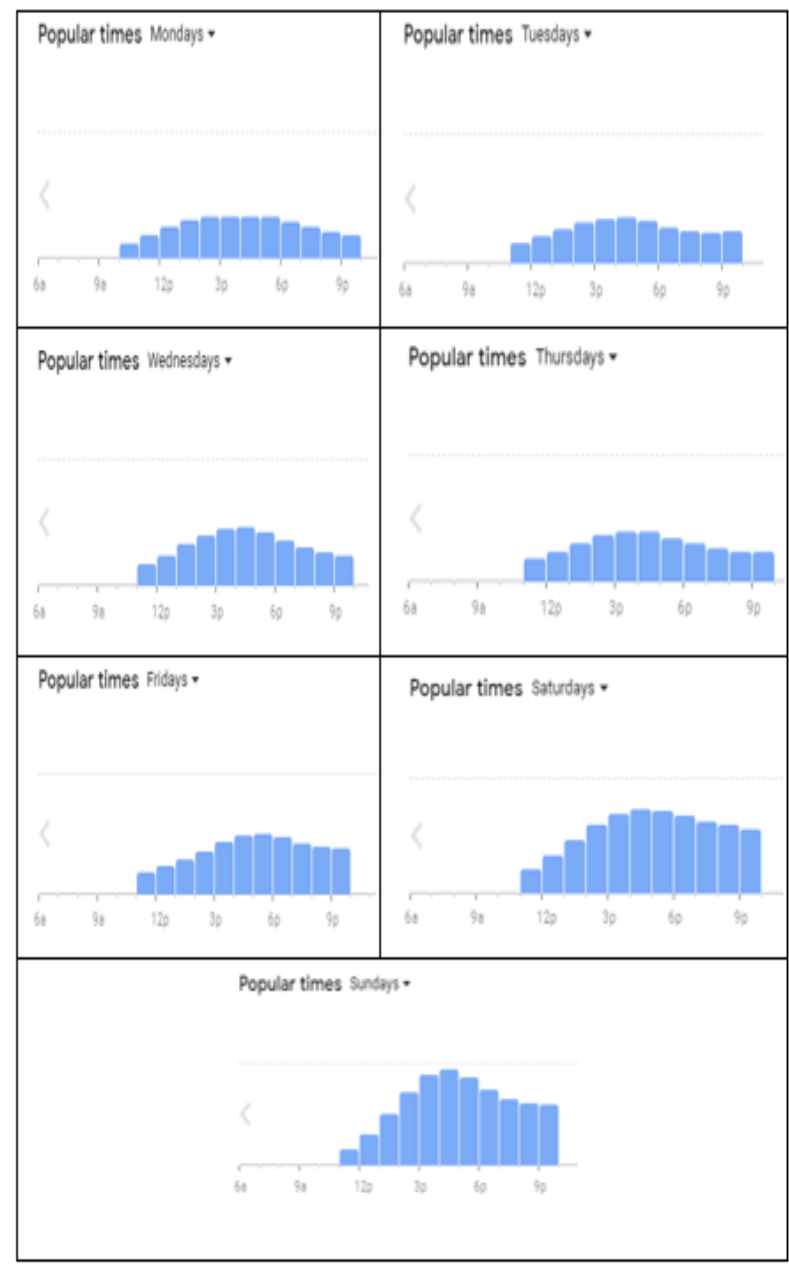

Fig. 14. Parking Trends and Demand of F-9 Park.
Fig. 14 depicts the map view of F-9 Park's parking lot whereas Fig. 15 shows the demand of parking in F-9 Park seven days a week along with peak times and peak days.

Fig. 16 shows the 3D view of F-9 Park's parking lot which is simulated on Anylogic Simulation Software.

Fig. 19 and Fig. 20 shows how vehicle used assigned parking coordinates and followed the directions along with the route to park at allotted spot or block.

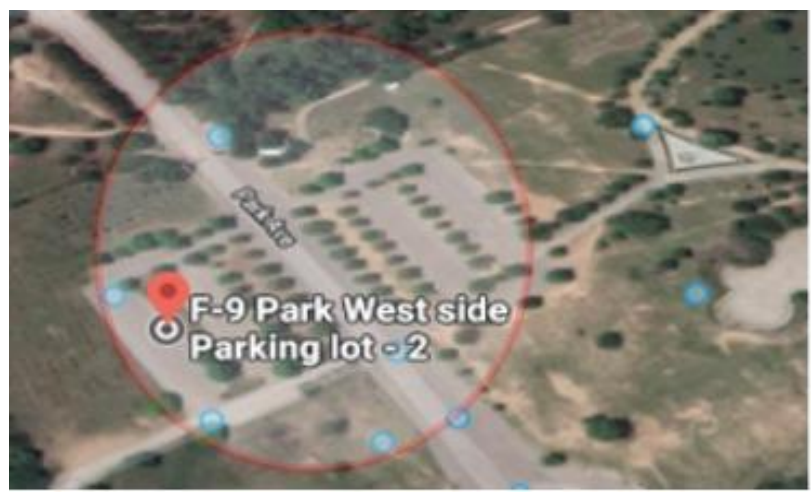

Fig. 15. Map and Ariel view of F-9 Park Parking loT.

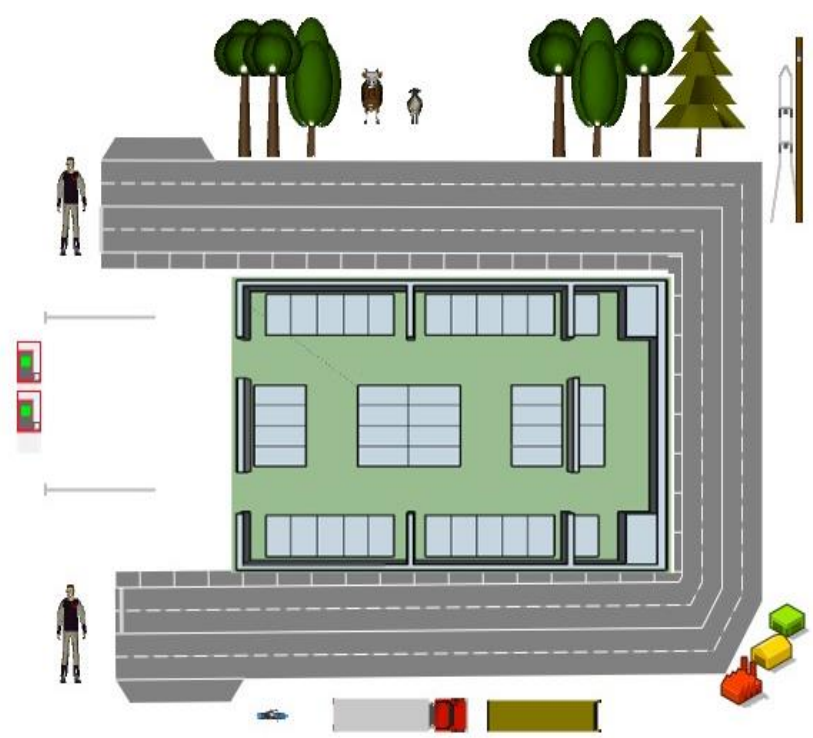

Fig. 16. 3D view of F-9 Park Parking Lot Sketched on AnyLogic Personal Learning Edition.

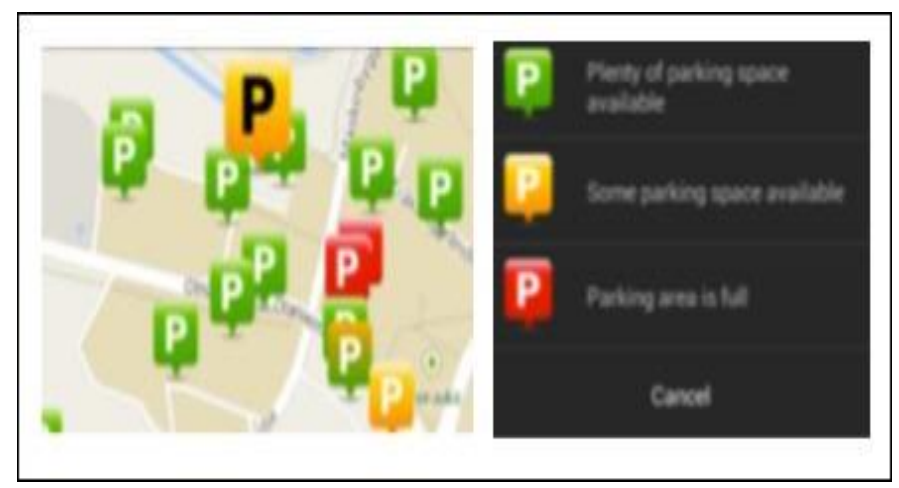

Fig. 17. Parking Spots Available at Requested Timestamp. 


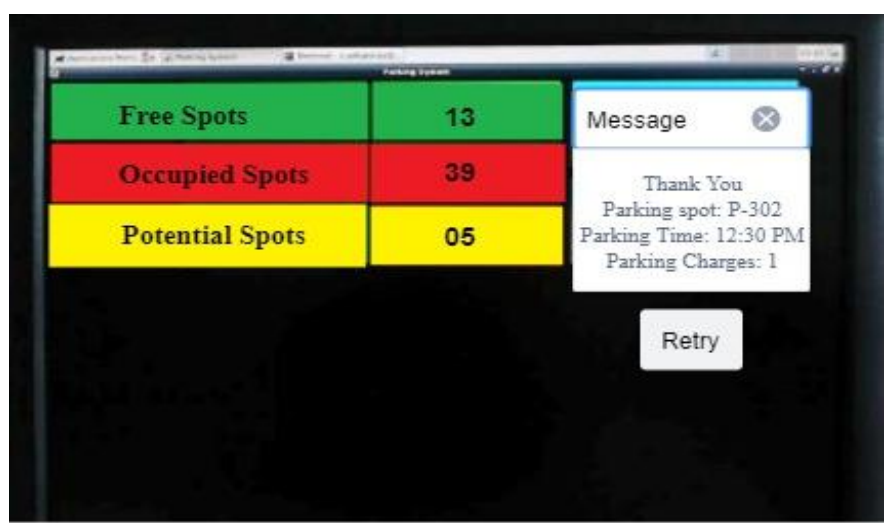

Fig. 18. Parking Spot Availability at Requested Timestamp.

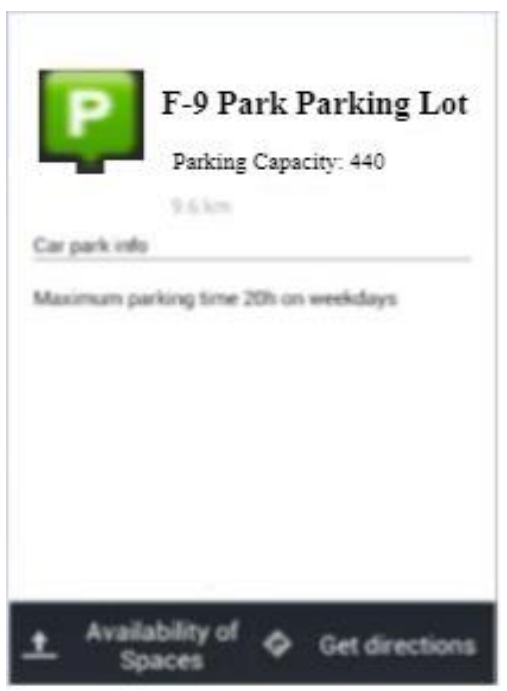

Fig. 19. Direction Coordinates of the Assigned Parking Spot.

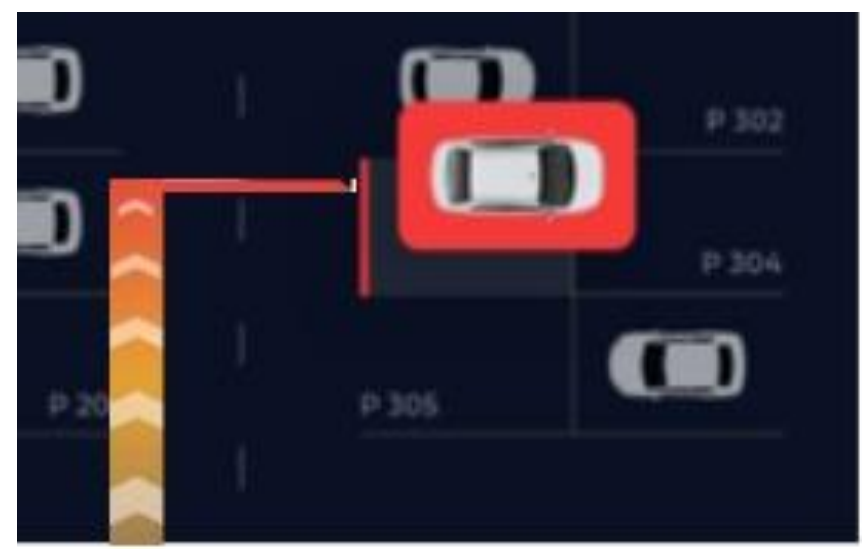

Fig. 20. Parking Route and Vehicle Parked at Assigned Block.

\section{CONCLUSION}

In this article, we present a model that helps in finding parking using CoT, GPS, WSN, and RFID within a specific geo-fence. Our proposed algorithm represents a step towards enhancing the ability of a Cloud-IoT based vehicle navigation system. It provides the probability of parking accessibility in the parking lot with their distance from the destination. Compared to other existing strategies, our approach considers exogenous external components such as variable (weather, time-zone), which leads to progress execution. If parking is inaccessible, our model calculates the waiting time. We illustrated the approach on data from city center (Islamabd) car parking. Using the test bed implementation as starting point our early results are reassuring, but the proposed model needs to be analyzed in circumstances when several vehicles look for the parking space. Our proposed model can be deployed on both existing and upcoming parking systems for use in real world. Further, the future traffic management systems would gain an improved and reliable framework for parking problems. The internet of things and cloud computing development offers rise to many modern potential results in areas of smart cities and smart transportation. With the progress of the internet of things (IoT), cloud computing, and other techniques. It is predicted that future traffic management systems will utilize reasonable cost and high efficiency to serve the public with more helpful, fast, accurate, and quality traffic administrative results.

\section{ACKNOWLEDGMENT}

This work is conducted under the supervison of Dr Baber Hayat, Assistant Professor at Department of Computer Science and IT in University of Lahore Pakistan. The authors would like to thank him for his valuable support and encourgement while carrying out the research. We also appreciate the feedback and review provided by $\mathrm{Mr}$ Asaad Subih on previous version of this manuscript.

\section{REFERENCES}

[1] G. Watene, C. Ndegwa, and D. Musiega, "A GIS-Based Parking Management and Dissemination System," Proceedings of Sustainable Research and Innovation Conference, pp. 117-124, 2014.

[2] Yogesh, Tayade, and MD. Patil, "Advance prediction of parking space availability and other facilities for car parks in smart cities, "International Research Journal of Engineering and Technology, vol. 3, no. 5, pp. 2225-2228, 2016.

[3] N. Ya'acob, A.M Azize, and N.M.R.N.Z Alam, "Parking system using geographic information system (GIS)," IEEE Conference on Systems, Process and Control (ICSPC), pp. 12-16, 2016.

[4] S.S Adhatarao, O. Alfandi, A. Bochem, and D. Hogrefe, "Smart Parking System for Vehicles," IEEE Vehicular Networking Conference (VNC), pp. 189-190, 2014.

[5] F. Caicedo, C. Blazquez, and P. Miranda," Prediction of parking space availability in real-time," Expert Systems with Applications, vol. 39, no. 8, pp. 7281-7290, 2012.

[6] Y. Asakura and M. Kashiwadani," Effects of parking availability information on system performance: a simulation model approach," Proceedings of VNIS'94-1994 Vehicle Navigation and Information Systems Conference. IEEE, pp. 251-254, 1994

[7] Levy, Nadav, and I. Benenson, "GIS-based method for assessing city parking patterns." Journal of Transport Geography, vol. 46, pp. 220-231, 2015.

[8] M. Silva, G. Martín, M. Gould, R. Montoliu, J.T Sospedra, and J. Huerta, "An occupancy simulator for a smart parking system: Developmental design and experimental considerations," ISPRS International Journal of Geo-Information, vol. 8, no. 5, pp. 212, 2019.

[9] Rinne, Mikko, S. Törmä, and D. Kratinov, "Mobile crowdsensing of parking space using geofencing and activity recognition," 10th ITS European Congress, Helsinki, Finland, pp. 16-19, 2014.

[10] Caliskan, Murat, A. Barthels, B. Scheuermann, and M. Mauve, "Predicting parking lot occupancy in vehicular ad hoc networks," IEEE 65th Vehicular Technology Conference-VTC2007-Spring, pp. 277-281, 2007.

[11] Pullola, Sherisha, P. K. Atrey, and A.E Saddik, "Towards an intelligent 
GPS-based vehicle navigation system for finding street parking lots," IEEE International Conference on Signal Processing and Communications, pp. 1251-1254, 2007.

[12] Froehlich, J. Edward, J. Neumann, and N. Oliver, "Sensing and predicting the pulse of the city through shared bicycling." Twenty-First International Joint Conference on Artificial Intelligence. 2009.

[13] Chen, Bei, F. Pinelli, M. Sinn, A. Botea, and F. Calabrese, "Uncertainty in urban mobility: Predicting waiting times for shared bicycles and parking lots," 16th International IEEE Conference on Intelligent Transportation Systems (ITSC 2013), pp. 53-58, 2013.

[14] Rajabioun, Tooraj, B. Foster, and P. Ioannou, "Intelligent parking assist," 21st Mediterranean Conference on Control and Automation. IEEE, pp. 1156-1161, 2013.

[15] Ji, Zhanlin, I. Ganchev, M. O'Droma, and X. Zhang, "A cloud-based intelligent car parking services for smart cities," 2014 XXXIth URSI General Assembly and Scientific Symposium (URSI GASS). IEEE, pp. $1-4,2014$.

[16] Leng, Ying, and L. Zhao, "Novel design of intelligent internet-of- vehicles management system based on cloud-computing and internet-ofthings." Proceedings of 2011 International Conference on Electronic \& Mechanical Engineering and Information Technology. IEEE, vol. 6, pp. 3190-3193, 2011.

[17] Qin, Erwa, Y. Long, C. Zhang, and L. Huang, "Cloud computing and the internet of things: Technology innovation in automobile service," International Conference on Human Interface and the Management of Information. Springer, pp. 173-180, 2013.

[18] K. Ashokkumar, B. Sam, R. Arshadprabhu and Britto, " Cloud-based intelligent transport system," Procedia Computer Science, vol. 50, pp. 58-63, 2015.

[19] P.S. Saarika, K. Sandhya and T. Sudha," Smart transportation system using IoT," International Conference on Smart Technologies For Smart Nation (SmartTechCon). IEEE, pp. 1104-1107, 2017.

[20] Cao, Hung, and M. Wachowicz, "The design of an IoT-GIS platform for performing automated analytical tasks," Computers, Environment, and Urban Systems, vol.74, pp. 23-40, 2019. 